Aortic annulus diameter was confirmed by a transesophageal echocardiography. With these preoperative findings, we concluded that the only possible strategy was a $29-\mathrm{mm}$ Sapien XT implantation via a transaortic approach.

Under general anesthesia, a small anterior right thoracotomy was performed in the second intercostal space. After opening and suspending the pericardium, the ascending aorta was exposed. Two purse-string sutures with a diameter of $1.5 \mathrm{~cm}$ were made with a 3-0 braided stitch and Teflon pledget reinforcement.

Puncture of the aorta was performed in the middle of the purse-string sutures. Under fluoroscopic guidance, an angiographic guide wire was inserted retrogradely through the aortic valve in the left ventricle. Because the direction of the guide wire is not perpendicular to the plane of the aortic valve, particular attention should be given to avoid possible lesions to the aortic sinuses and aortic wall. A $6 \mathrm{~F}$ sheath was then placed on the guide wire through the aortic valve to exchange the guide wire with an extra-stiff one, following the already described transfemoral implantation technique. ${ }^{5}$ The 26F Ascendra 2 sheath (Edwards Lifesciences) was inserted in the ascending aorta (Figure 1, $A$ ) to perform subsequent balloon aortic valvuloplasty and valve deployment.

Aortic valvuloplasty was carried out with a $20-\mathrm{mm}$ balloon during 180 beats/min-induced ventricular tachycardia (Figure 1, B). A 29-mm Sapien XT valve was prepared on the Ascendra 2 delivery system with its inflow portion directed toward the tip of the catheter (ie, in the opposite position of a transapical procedure).

The prosthesis was then placed in the correct position (50\% below and $50 \%$ above the aortic annulus), and valve deployment was performed under induced ventricular tachycardia (Figure 1,C). Correct valve positioning and the absence of residual aortic valve regurgitation were confirmed by postprocedural aortic angiography (Figure $1, D$ ) and intraoperative transesophageal echocardiography (Figure 1,E).

The sheath was then removed, and the aortic purse-string sutures were tightened under induced ventricular tachycardia. The patient had an uneventful recovery and was discharged in good general and clinical conditions.

\section{CONCLUSIONS}

Transaortic implantation of the Sapien XT valve using the Ascendra 2 system via a small right anterior thoracotomy may represent a valid alternative for patients with severe aortic valve stenosis who are not eligible for surgical aortic valve replacement and who cannot undergo a retrograde transarterial or a transapical TAVI.

\section{References}

1. Leon MB, Smith CR, Mack M, Miller C, Moses JW, Svensson LG, et al. Transcatheter aortic valve implantation for aortic stenosis in patients who cannot undergo surgery. $N$ Engl J Med. 2010;363:1597-607.

2. Bleiziffer S, Piazza N, Mazzitelli D, Opitz A, Bauernschmitt R, Lange R. Apicalaccess-related complications associated with trans-catheter aortic valve implantation. Eur J Cardiothorac Surg. 2011;40:469-74.

3. De Robertis F, Asgar A, Davies S, Delahunty N, Kelleher A, Trimlett R, et al. The left axillary artery - a new approach for transcatheter aortic valve implantation. Eur J Cardiothorac Surg. 2009;36:807-12.

4. Latsios G, Gerkens U, Grube E. Transaortic transcatheter aortic valve implantation: a novel approach for the truly "no-access option" patients. Catheter Cardiovasc Interv. 2010;75:1129-36.

5. Cribier A, Litzler PY, Eltchaninoff H, Godin M, Tron C, Bauer F, Bessou JP. Technique of transcatheter aortic valve implantation with the Edwards-Sapien heart valve using the transfemoral approach. Herz. 2009;34:347-56.

\title{
A simplified technique for total anomalous pulmonary venous connection repair associated with functional single ventricle
}

\author{
Naritaka Kimura, MD, Ayumu Masuoka, MD, Toshiyuki Katogi, MD, and Takaaki Suzuki, MD, Saitama, \\ Japan
}

Surgical repair of total anomalous pulmonary venous connection (TAPVC) with single ventricle remains challenging because of the risk of late pulmonary venous obstruction. ${ }^{1,2}$

\footnotetext{
From the Department of Pediatric Cardiac Surgery, Saitama International Medical Center, Saitama Medical University, Saitama, Japan.

Disclosures: Authors have nothing to disclose with regard to commercial support.

Received for publication Sept 4, 2011; revisions received Nov 10, 2011; accepted for publication Dec 8, 2011; available ahead of print Jan 13, 2012.

Address for reprints: Naritaka Kimura, MD, 1397-1 Yamane, Hidaka-shi, Saitama 350-1298, Japan (E-mail: naritaku@mvf.biglobe.ne.jp).

J Thorac Cardiovasc Surg 2012;143:1455-7

$0022-5223 / \$ 36.00$

Copyright (c) 2012 by The American Association for Thoracic Surgery

doi:10.1016/j.jtcvs.2011.12.012
}

Since 2007, we have used the vertical vein to establish the continuity between the common atrium and the pulmonary vein without cutting into the pulmonary venous confluence. This report describes the outcome associated with this simplified technique for TAPVC repair.

\section{CLINICAL SUMMARY}

Six patients with single ventricle and TAPVC underwent TAPVC repair in the primary operation between October 2007 and September 2010. The institutional review board at Saitama International Medical Center, Saitama Medical University, Saitama, Japan, approved this retrospective 

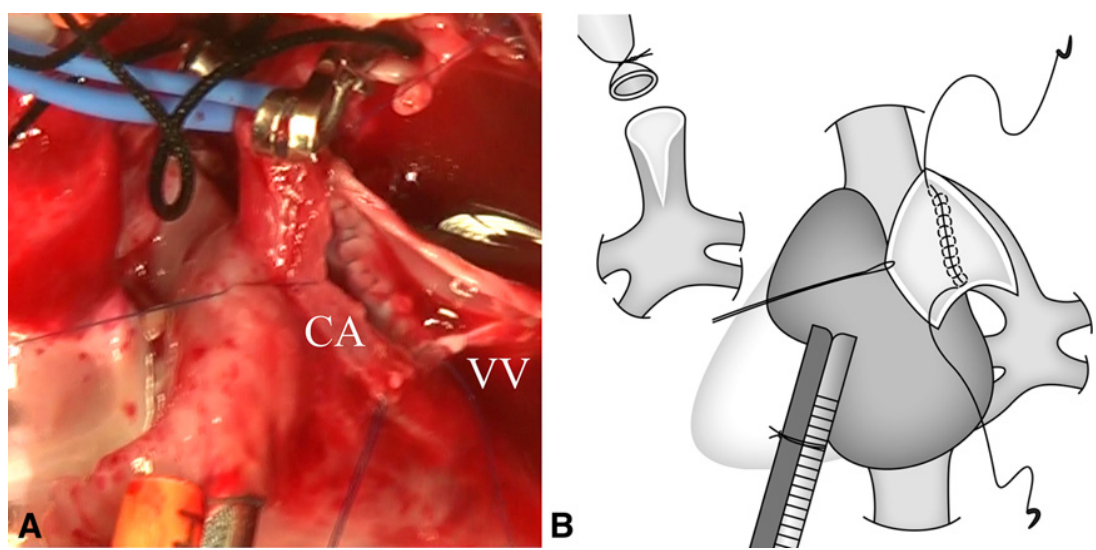

FIGURE 1. Operative view (A) and diagram (B) of total anomalous pulmonary venous connection repair with the vertical vein $(V V)$. $C A$, Common atrium.

study and waived the need for consent by the patient's guardians. Three of 6 patients were neonates, and 3 of 6 patients were male. The mean age at the operation was $29 \pm$ 28 days (range, 14-85 days), and the mean body weight was $3.2 \pm 0.6 \mathrm{~kg}$ (range, $2.3-4.1 \mathrm{~kg}$ ). All patients had the diagnosis of right atrial isomerism and extracardiac type TAPVC. The type of TAPVC was supracardiac in 5 patients and was mixed in 1 patient.

All patients underwent TAPVC repair through a median sternotomy and were placed on cardiopulmonary bypass. Patients were cooled to $18^{\circ} \mathrm{C}$ for deep hypothermic circulatory arrest. The vertical vein was dissected thoroughly and then ligated and cut off as long as possible from the pulmonary venous confluence. The pulmonary veins and pulmonary venous confluence were minimally dissected. The cut end of the vertical vein was trimmed, and a vertical incision was made longitudinally without extending into the pulmonary venous confluence. The corresponding common atrial wall was incised sufficiently. The incised vertical vein and common atrial wall were anastomosed with a 7-0 polypropylene running suture (Figure 1). Concomitant procedures were systemic-to-pulmonary shunting in all patients, pulmonary arterial banding in 1 patient, central pulmonary artery plasty in 1 patient, and common atrioventricular valve plasty in 1 patient. The mean cardiopulmonary bypass time was $154 \pm 50$ minutes, the mean aortic crossclamp time was $47 \pm 19$ minutes, and the mean circulatory arrest time was $27 \pm 3$ minutes.

The median follow-up period was 15 months (range, 2-36 months). There was 1 early death from sepsis. One late death occurred as a result of pneumonia at 3 months after bidirectional Glenn shunting. There was no evidence of pulmonary venous obstruction in either case. In the remaining 4 patients, no recurrent pulmonary venous obstruction was detected by Doppler echocardiography, cardiac catheterization, or 3-dimensional computed tomography (Figure 2). Two patients underwent Fontan operations, and 2 patients underwent bidirectional Glenn shunting.

\section{DISCUSSION}

Establishment of an adequately large and tension-free anastomosis is critical for TAPVC repair, and trauma to the pulmonary vein endothelium must be avoided to reduce the risk of subsequent pulmonary venous obstruction. Morales and colleagues ${ }^{3}$ have advocated limited dissection to the pulmonary vein confluence with minimal manipulation of the pulmonary veins, because the dissection and manipulation of pulmonary veins themselves increases the inflammatory and eventual adhesive or fibrotic reaction of and around pulmonary veins and may also contribute to pulmonary venous obstruction. In patients with single ventricle, the pulmonary venous confluence tends to be smaller, which can increase the risk of

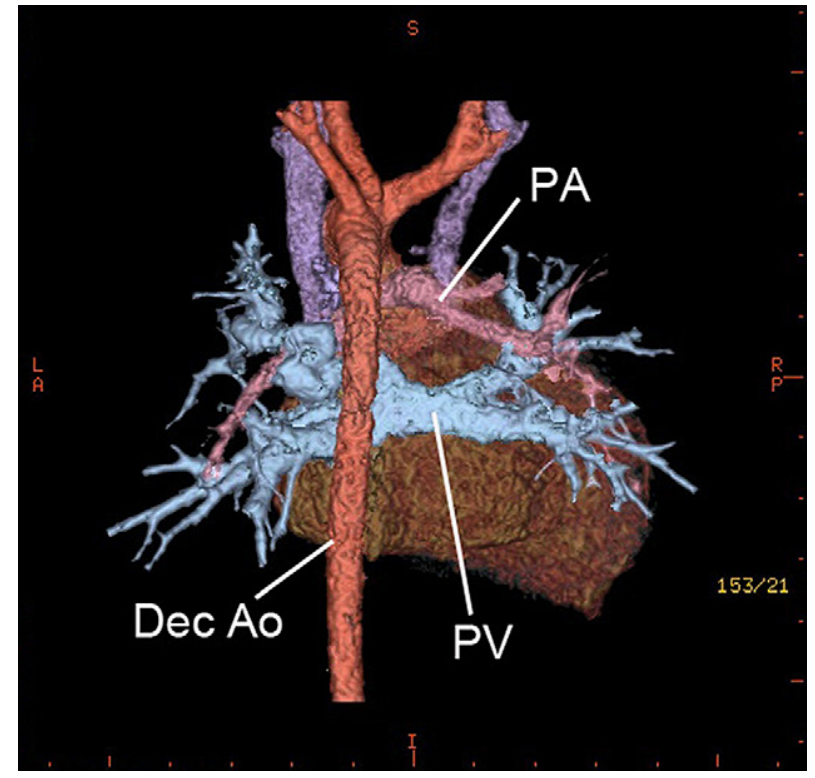

FIGURE 2. Postoperative computed tomographic scan showing good communication between a common atrium and the pulmonary venous confluence. There is no anastomotic stenosis. PA, Pulmonary artery; Dec Ao, descending aorta; $P V$, pulmonary vein. 
complications associated with excessive dissection. ${ }^{4}$ In addition, a suture line close to the individual pulmonary veins is mandatory.

The potential advantage of our technique is that the suture line does not approach the individual pulmonary venous orifice, thereby avoiding trauma to the pulmonary venous endothelium and preventing reactive intimal proliferation, even in the context of a tiny pulmonary venous confluence. Further, limited dissection of the pulmonary venous confluence and the individual pulmonary veins results in maintenance of adequate alignment of the pulmonary veins relative to the atrial wall, thereby avoiding torsion and rotation. In this manner, we are able to choose the best corresponding position of the atrial wall for anastomosis, because the single-ventricle heart has a functional common atrium.

By contrast, Yoshimura and colleagues ${ }^{5}$ performed sutureless pericardial repair of TAPVC associated with right atrial isomerism as a primary operation and reported good results. Primary sutureless repair may seem to be a good option, but because there is considerable variation in this group of diseases, our technique could be considered the better alternative in some cases. Further analysis is required determine the best manner to achieve TAPVC repair.

\section{CONCLUSIONS}

Our technique for TAPVC repair, which uses a vertical vein without cutting into the pulmonary venous confluence, showed favorable midterm results. This technique may be the strategy of choice for extracardiac type TAPVC repair associated with single-ventricle heart.

\section{References}

1. Gaynor JW, Collins MH, Rychik R, Gaughan JP, Spray TL. Long-term outcome of infants with single ventricle and total anomalous pulmonary venous connection. J Thorac Cardiovasc Surg. 1999;117:506-14.

2. Kelle AM, Backer CL, Gossett JG, Kaushal S, Mavroudis C. Total anomalous pulmonary venous connection: results of surgical repair of 100 patients at a single institution. J Thorac Cardiovasc Surg. 2010;139:1387-94.e3.

3. Morales DL, Braud BE, Booth JH, Graves DE, Heinle JS, McKenzie ED, et al. Heterotaxy patients with total anomalous pulmonary venous return: improving surgical results. Ann Thorac Surg. 2006;82:1621-8.

4. Yun TJ, Al-Radi OO, Adatia I, Caldarone CA, Coles JG, Williams WG, et al. Contemporary management of right atrial isomerism: effect of evolving therapeutic strategies. J Thorac Cardiovasc Surg. 2006;131:1108-13.

5. Yoshimura N, Oshima Y, Henaine R, Matsuhisa H. Sutureless pericardial repair of total anomalous pulmonary venous connection in patients with right atrial isomerism. Interact Cardiovasc Thorac Surg. 2010;10:675-8.

\title{
Prosthetic aortic valve-pexy: Stitch closure of the aortic valve in a patient with a ventricular assist device
}

\author{
Salil V. Deo, MS, MCH, ${ }^{a}$ Soon J. Park, MD, ${ }^{a}$ Lawrence J. Sinak, MD, ${ }^{b}$ and Alfredo L. Clavell, MD, \\ Rochester, Minn
}

Intermittent opening of the mechanical aortic valve after placement of a ventricular assist device (VAD) can lead to an increased risk of thromboembolism. It has been recommended to close the aorta with a patch or replace it with a bioprosthesis. ${ }^{1,2}$ Both these methods, however, increase the ischemic time. A single-stitch method to close the mechanical aortic valve has been described ${ }^{3}$; however, placement of the suture as illustrated in the article is technically very difficult. We therefore describe our modification as used in a patient with a mechanical aortic valve undergoing VAD placement and include intraoperative photographs and an illustration.

\footnotetext{
From the Divisions of Cardiovascular Surgery ${ }^{\mathrm{a}}$ and Cardiovascular Disease, ${ }^{\mathrm{b}}$ Mayo Clinic, Rochester, Minn.

Disclosures: The authors do not have any conflict of interest

Received for publication March 2, 2011; revisions received March 24, 2011; accepted for publication April 18, 2011; available ahead of print Jan 24, 2012.

Address for reprints: Soon J. Park, MD, Consultant, Division of Cardiovascular Surgery, Mayo Clinic, 100 2nd St SW, Rochester, MN 55905 (E-mail: park.soon@ mayo.edu).

J Thorac Cardiovasc Surg 2012;143:1457-9

$0022-5223 / \$ 36.00$

Copyright (c) 2012 by The American Association for Thoracic Surgery

doi:10.1016/j.jtcvs.2011.04.051
}

\section{CLINICAL SUMMARY}

A patient with medically refractory congestive heart failure was referred for placement of a VAD as a destination therapy. He had previously undergone ascending aorta replacement with a Dacron polyester fabric tube graft and aortic valve replacement with a St Jude bileaflet mechanical prosthesis (St Jude Medical, St.Paul, Minn). Surgery was conducted with hypothermic cardiopulmonary bypass, and diastolic cardiac arrest was achieved with cold blood cardioplegia after clamping of the ascending aorta. The aorta was opened transversely to gain exposure of the mechanical valve (Figure 1, A, blue arrows). A 3-0 GORE-TEX suture (W. L. Gore \& Associates, Inc, Flagstaff, Ariz) was inserted at the aortic annulus from the aortic side to the ventricular side. The sewing needle was then retrieved from the gap between the valve leaflet and the sewing ring (Figure 1, $A$, white arrow). This was then repeated on the opposite side. It is essential to do this perpendicular to the opening plane of the leaflets, as depicted in Figure 1, $B$ and $C$. As the suture was pulled, the leaflets closed (Figure $1, B$ and $C$ ). Care must be taken to remove any slack of the suture when the 